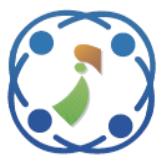

\title{
Prioritization of Wind Energy Data with Analytical Hierarchy Process (AHP)
}

\author{
Sakon Klongboonjit ${ }^{1 *}$ \\ Tossapol Kiatcharoenpol ${ }^{1}$ \\ ${ }^{1}$ Industrial Engineering Department, School of Engineering, \\ King Mongkut's Institute of Technology Ladkrabang, Bangkok, Thailand \\ * Corresponding author's Email: sklongboonjit@hotmail.com
}

\begin{abstract}
Wind energy potential is the main data to making decision for green energy projects in resident areas. The decision makers generally prioritize wind energy of alternative areas with data of wind power that are hard collected. In this study, the AHP method is introduced to prioritize wind energy of alternative areas with data of average wind velocity generally receiving from the secondary data sources. With the example of 13 alternative areas in the south of Thailand, the data of average wind velocity can be used to construct the AHP pairwise comparison matrix. Finally, the priority values of these 13 alternative areas are calculated with C.R. $=0.1157$ and the wind energy priority of alternative areas is prioritized. The priority results with the data of average wind velocity are really similar to the priority results with the data of wind power.
\end{abstract}

Keywords: Analytical hierarchy process (AHP), Wind energy, Wind energy potential, Wind energy priority.

\section{Introduction}

Everyone needs the energy for his or her daily life. For Thailand, the final total energy consumption in 2020 was about 36,928 ktoe or US\$ 20,327.52 million [1]. As shown in Fig. 1, fossil fuel, renewable energy, traditional renewable energy and importing hydroelectric power represented $76.65 \%, 15.13 \%, 4.94 \%$ and $3.28 \%$ of the final total energy consumption in 2020, respectively.

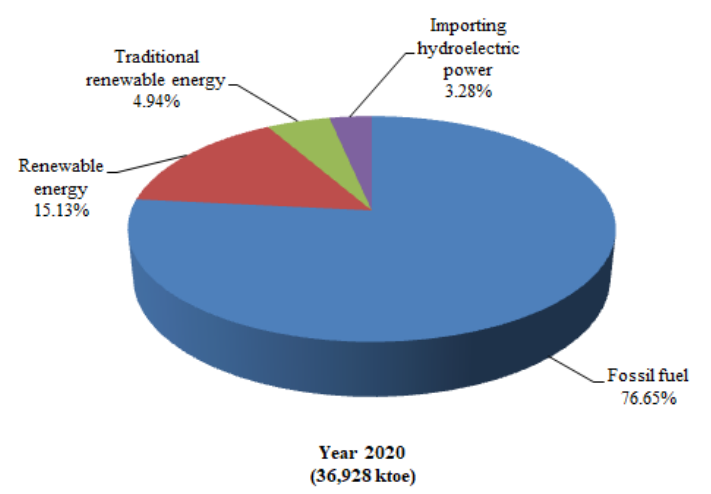

Figure. 1 The final total energy consumption by types of Thailand in 2020 [1]
To decrease the final total energy consumption by fossil fuel, renewable energy such as solar energy or wind energy should be increasingly used. Since Thailand is located near the equator that means both solar energy and wind energy can be really alternative energy sources for Thailand. Some researchers prefer study with wind energy to solar energy since wind blows all day and night although the average of wind speed in Thailand is around 3-5 $\mathrm{m} / \mathrm{s}$ (Low to moderate level). That means wind can continuously generate energy all 24 hours in a day. There are many researchers studying on the wind potential of Thailand. Thitipong, Adun and Arne [2] used hourly wind speed data from year 2008 to 2010 at the height of $10 \mathrm{~m}, 30 \mathrm{~m}$ and $40 \mathrm{~m}$ of Ubonratchathani province in Thailand to determine the potential of wind power generation. Sakkarin and Somchai [3] reviewed the status of wind energy in Thailand and concluded that wind energy was agreed to be one of good alternative energy sources to generate electric power. Pham and Thananchai [4] statistically analyzed one year wind measurement data of three sites to investigate wind energy potential at high level at the height of $65 \mathrm{~m}, 90 \mathrm{~m}$ and $120 \mathrm{~m}$. The results showed that the wind 
turbines with low cut-in wind speed were strongly recommended to install at these three sites. From [24], there were not secondary data of wind speed for researchers making decision or analyzing wind speed data. These researchers had to collect and measure all related wind data by themselves with long data collection time and high budget cost. These are important obstacles for people who have not any wind measuring instruments and enough budgets.

According to above studies, it is clearly that if there are secondary wind data, these wind energy data should be prioritized for conveniently using by decision makers for renewable energy investments. To prioritize data, Analytical Hierarchy Process (AHP) that is one of efficient and simply technique, should be applied to many types of data. Since AHP was developed in the 1970s, AHP has been applied to many cases. Mathew [5] applied AHP for priority setting and resource allocation in the industrial $R \& D$ environment so that $R \& D$ projects were selected under multi-criteria decision. Mikko, Mauno, Jyrki and Miika [6] set strategy plan for forest certification by using AHP integrating with SWOT analysis. Handfield, Walton, Sroufe and Melnyk [7] integrated environment criteria with other criteria and used AHP to help purchasing managers in making decision for prioritizing all suppliers. Alan, David, Tsaletseng and Mark [8] combined AHP with a Life Cycle Management and applied this method like decision support tool to establish health care waste management systems. Karimi, Mehrdadi, Hashemian, Mabi and Tavakkoli [9] presented the application of AHP and Fuzzy AHP to prioritize and select the best wastewater treatment process among five alternatives. Ozgur and Birol [10] applied AHP for energy resource planning to build environment in one district under multi-level criteria. With the different point of views, local people and local government agreed with solar energy investments, while industry selected to invest clean technology in geothermal power plants and de-centralized lignite power plants. Jose [11] developed the AHP-express method to reduce the numbers of $n$ - alternative comparisons. Calculation time of this method was faster than calculate with conventional AHP method and this method should be interesting for decision makers. Romulo, Eudemario and Alex [12] applied AHP with multi-criteria to wind farm project. AHP method could prioritize and group all 27 territories for wind farm installation based on the values of wind speed. With researches [5-12], it clearly that AHP is really one of good methods to apply with decision making processes for project investment. However, there may be some bias from related persons who scores the AHP scales 1-9 during AHP pairwise comparison process.

\section{Purpose}

According to these researchers' studying [2] [12], it is possible to introduce AHP to analyze the wind energy data within alternative areas. However, the high cost of wind data collection and bias AHP scores from AHP pairwise comparison are main obstacles for applying to wind energy project investment in rural areas which lack of the budget and experts. Therefore, the main purpose of this study is to present the simply way with AHP to analyze secondary wind data for alternative areas prioritization. With using secondary data of wind data collected by Department of Alternative Energy Development and Efficiency, Ministry of Energy, Thailand [13], the decision makers can reduce a lot of project budget and avoid bias AHP scores for green energy projects in Thailand.

\section{Research methodology}

To prioritizing wind energy data, there are five main steps as following: 1) Select interesting areas for wind energy investment and collect wind energy data, 2) Calculate pairwise distance values for wind energy data of interesting areas, 3) Convert pairwise distance values into Scale 1 to 9 and construct AHP pairwise comparison matrix, 4) Construct AHP normalized matrix and calculate priority vector for each interesting areas and 5) Check consistency of results.

\subsection{Select alternative areas for wind energy investment and collect wind energy data}

In this first step, the secondary data of wind energy [13] for alternative areas are searched. These data are the average wind velocity along 12 months of a year from 41 wind data collection centers. There are 10, 3, 9, 6 and 13 wind data set for north, middle and west, north-east, east and south of Thailand, respectively. All data is for the wind speed at the height level of $40 \mathrm{~m}$ that is properly for local resident to develop green projects in his/her own resident areas. The map of average wind velocity in Thailand at the height level of $40 \mathrm{~m}$ as shown in Fig. 2

\subsection{Calculate pairwise distance values for wind energy data of interesting areas}

In this stage, the wind energy data of alternative areas from the first stage are pairwise calculated 
with the Euclidean distance in Eq. (1) to receive the pairwise distance value of wind energy for alternative area $i$ and $j\left(D_{i j}\right)$. This pairwise distance value $\left(D_{i j}\right)$ depends on the average wind velocity of alternative area $i$ of the $k^{\text {th }}$ month $\left(x_{i k}\right)$ and the average wind velocity of alternative area $j$ of the $k^{\text {th }}$ month $\left(y_{i k}\right)$.

$$
D_{i j}=\sqrt{\sum_{k=1}^{12}\left(y_{i k}-x_{i k}\right)^{2}}, i \neq j
$$

To compare the potential or quality of wind in the alternative area $i$ with $j\left(Q_{i j}\right)$, this value is calculated with the Eq. (2) where the quality of wind in the alternative area $\mathrm{i}$ is equal to it in the alternative area $j$ if $Q_{i j}=0$, the quality of wind in the alternative area $j$ is higher than it in the alternative area $i$ if $Q_{i j}>0$ and the quality of wind in the alternative area $i$ is higher than it in the alternative area $j$ if $Q_{i j}<0$.

$$
Q_{i j}=\sum_{k=1}^{12}\left(y_{i k}-x_{i k}\right), i \neq j
$$

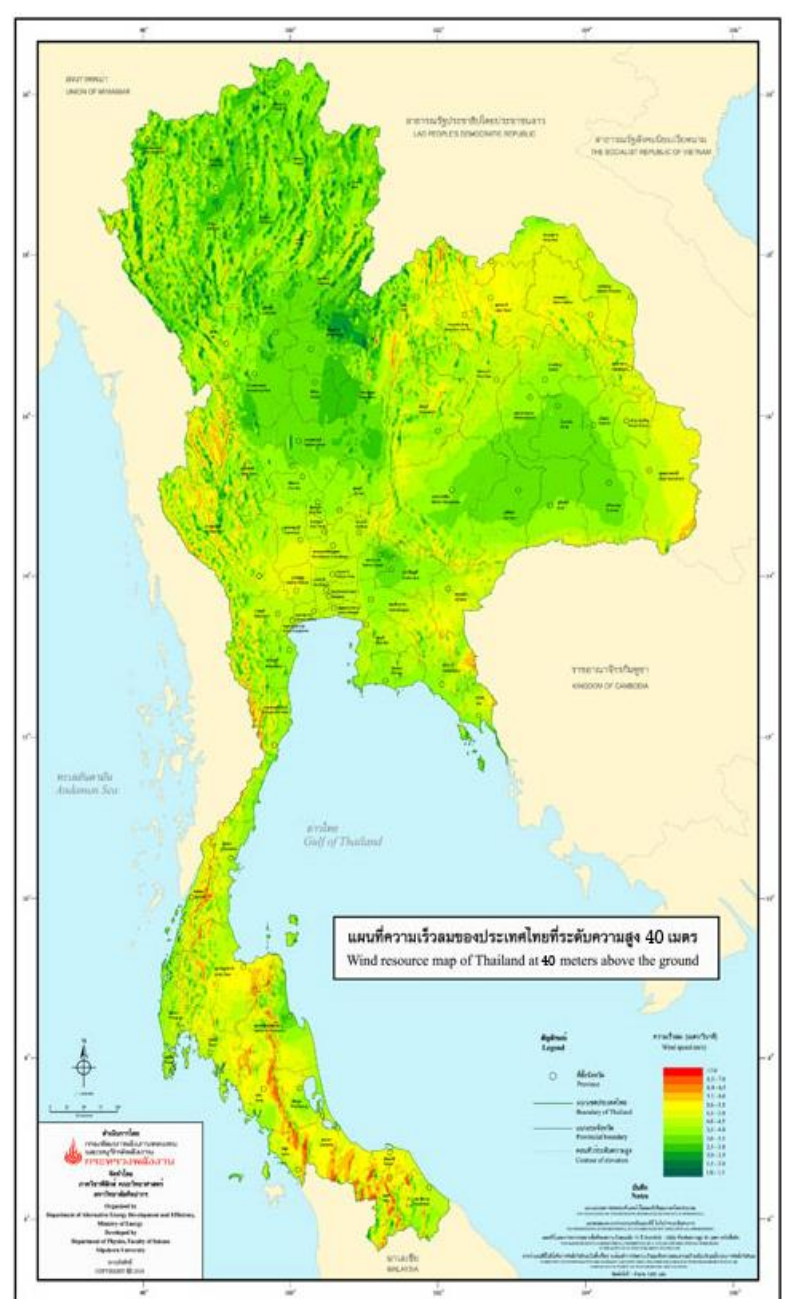

Figure. 2 The map of average wind velocity in Thailand at the height level of $40 \mathrm{~m} \mathrm{[13]}$
3.3 Convert pairwise distance values $\left(D_{i j}\right)$ into AHP scale 1 to 9 and construct AHP pairwise comparison matrix

In this Stage, all $D_{i j}$ values have to be firstly converted into Saaty's AHP scale 1-9 and the AHP pairwise comparison matrix is finally constructed with 3 sub-steps:

Step 1: Convert pairwise distance value $\left(D_{i j}\right)$ into AHP scale 1-9 $\left(L_{i j}\right)$

With this step, all pairwise distance values $\left(D_{i j}\right)$ are converted into AHP scale 1-9 $\left(L_{i j}\right)$ with the Eq. (3)

$$
L_{i j}=\operatorname{round}\left[1+\frac{8 D_{i j}}{\max \left\{D_{i j}\right\}}\right], i \neq j
$$

Step 2: Calculate the AHP pairwise comparison value of the alternative area $i$ and $j\left(C_{i j}\right)$

From the results of the Eqs. (2) and (3), the $C_{i j}$ value that is the AHP pairwise comparison value of the alternative area $i$ and $j$, is evaluated with the Eq. (4).

$$
\begin{gathered}
C_{i j}=C_{j i}=1 \text { for } Q_{i j}=0 \text { or } D_{i j}=0 \text { and } i \neq j \\
C_{j i}=L_{i j} \text { and } C_{i j}=\frac{1}{L_{i j}} \text { for } Q_{i j}>0 \text { and } i \neq j \\
C_{j i}=\frac{1}{L_{i j}} \text { and } C_{i j}=L_{i j} \text { for } Q_{i j}<0 \text { and } i \neq j \\
C_{i i}=1 \text { for } i=j
\end{gathered}
$$

Step 3: Construct the AHP pairwise comparison matrix

The AHP pairwise comparison matrix is finally constructed with all $C_{i j}$ values. The AHP pairwise comparison matrix is shown as in Fig. 3.

\subsection{Construct AHP normalized matrix and

\begin{tabular}{|c|c|c|c|c|c|}
\hline & A1 & A2 & A3 & & An \\
\hline A1 & $C_{11}=1$ & $C_{12}$ & $C_{13}$ & $\ldots$ & $C_{l n}$ \\
\hline A2 & $C_{21}$ & $C_{22}=1$ & $C_{23}$ & $\ldots$ & $C_{2 n}$ \\
\hline A3 & $C_{31}$ & $C_{32}$ & $C_{33}=1$ & $\ldots$ & $C_{3 n}$ \\
\hline & - & r & $\cdot$ & 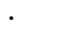 & $\cdot$ \\
\hline & . & . & . & $\cdot$ & · \\
\hline$A$ & $C_{n 1}$ & $C_{n 2}$ & $C_{n 3}$ & $\ldots$ & $C_{n n}=1$ \\
\hline
\end{tabular} calculate priority vector for each interesting areas}

To construct the AHP normalized matrix, each value in each cell in the AHP pairwise comparison matrix is divided by its corresponding column sum. The AHP normalized matrix is shown in Fig. 4.

Figure. 3 The AHP pairwise comparison matrix of $n$ alternative areas 


\begin{tabular}{|c|c|c|c|c|}
\hline A1 & $\mathrm{A} 2$ & A3 & $\ldots$ & An \\
\hline$N_{l 1}$ & $N_{12}$ & $N_{13}$ & $\ldots$ & $N_{l n}$ \\
\hline$N_{21}$ & $N_{22}$ & $N_{23}$ & $\ldots$ & $N_{2 n}$ \\
\hline$N_{31}$ & $N_{32}$ & $N_{33}$ & $\ldots$ & $N_{3 n}$ \\
\hline · & . & . & . & - \\
\hline . & . & $\cdot$ & $\cdot$ & . \\
\hline$\frac{\cdot}{N_{n l}}$ & $N_{n 2}$ & $\frac{\cdot}{N_{n 3}}$ & . & $\frac{\cdot}{N_{n n}}$ \\
\hline
\end{tabular}

Figure. 4 The AHP normalized matrix of $n$ alternative areas

The priority vector for $\mathrm{n}$ alternative areas, $\left[P_{A 1,} P_{A 2}, P_{A 3, \ldots}, P_{A n}\right]^{T}$, is determined by averaging the values in every row of the AHP Normalized Matrix.

$$
P_{A i}=\frac{\sum_{j=1}^{n} N_{i j}}{n}, i \neq j
$$

\subsection{Check consistency of results}

To check consistency of the priority values in the priority vector, the consistency ratio (C.R.) should be computed with the Eqs. (6) to (9). The temporary values $\left(B_{i}\right)$ are firstly calculated with the Eq. (6). Next, the average value $\left(\lambda_{\max }\right)$ of $B_{i}$ 's is calculated with the Eq. (7) and the consistence index (C.I.) is calculated with the Eq. (8). Finally, the consistency ratio (C.R.) is estimated with the Eq. (9).

$$
\begin{gathered}
B_{i}=\frac{\sum_{j=1}^{n} P_{A j} C_{i j}}{P_{A i}}, i=1 \text { to } n \\
\lambda_{\max }=\frac{\sum_{i=1}^{n} B_{i}}{n} \\
\text { C.I. }=\frac{\left(\lambda_{\max }-n\right)}{(n-1)} \\
\text { C.R. }=\frac{\text { C.I. }}{\text { R.I. }}
\end{gathered}
$$

Since the weather data generally have a lot of uncontrollable factors during data collecting, so it should have some uncontrollable factors within the data of average wind velocity along 12 months of a

Table 1. The Saaty's Random Index (R.I.) and number of

\begin{tabular}{|c|c|c|c|c|c|c|}
\hline $\begin{array}{c}\text { Number of } \\
\text { Alternative } \\
\text { s (n) }\end{array}$ & 2 & 3 & 4 & 5 & 6 & 7 \\
\hline R.I. & 0.00 & 0.58 & 0.90 & 1.12 & 1.24 & 1.32 \\
\hline
\end{tabular}

\begin{tabular}{|c|c|c|c|c|c|c|}
\hline $\begin{array}{c}\text { Number of } \\
\text { Alternative } \\
\text { s (n) }\end{array}$ & 8 & 9 & 10 & 11 & 12 & 13 \\
\hline R.I. & 1.41 & 1.45 & 1.49 & 1.51 & 1.48 & 1.56 \\
\hline
\end{tabular}

year from 41 wind data centers, the median of C.R. can be up to 0.12 for a $95 \%$ confidence interval [8]. Therefore, the C.R. of less than 0.12 is considered as an adequate indication of consistency.

\section{Results and discussion}

In this study, thirteen alternative areas in the south of Thailand (Fig. 5) are considered their wind energy potential. Since Andaman Sea is on the left side and Gulf of Thailand is on the right side of Thailand south areas that make these 13 alternative areas really interesting potential areas for wind energy projects.

The average wind velocity data at the height level of $40 \mathrm{~m}$ for these 13 alternative areas [13] and their wind power values are shown in Table 2 . Generally, the wind energy potential of each area can be evaluated by wind power value. The area with higher wind power value has more energy potential than other areas with lower wind power. However, wind power value depends on wind velocity value and these wind velocity data are easier searched as the secondary data than the wind power data, it would be nice if the wind velocity data are used to evaluate wind energy potential replacing of the wind power data. To evaluate the wind energy potential, the AHP is tried to apply with the wind velocity data of these 13 alternative areas in this study.

According to the data of wind power in Table 2, the wind energy potential of 13 alternative areas can be clearly ranked from the highest priority to lowest priority as follows: $W 1, W 2, W 3, W 4, W 5, W 6, W 7$, $W 8, W 9, W 10, W 11, W 12$ and $W 13$, respectively.

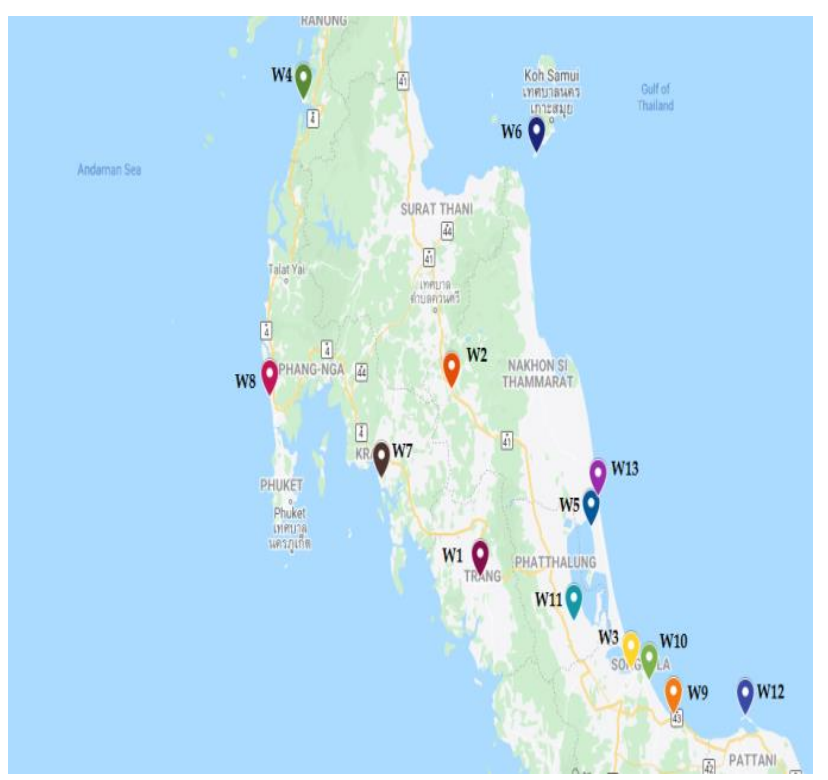

Figure. 5 The location of 13 alternative areas in the south of Thailand 
With the AHP, researchers expect to get the calculating results that can prioritize the wind energy potential without using wind power data. If it is possible to use AHP to evaluate wind energy potential, it will be very useful to apply this method to site selection of wind energy projects in the future.

With the Eqs. (1) and (2), the pairwise distance value $\left(D_{i j}\right)$ and the quality value of wind energy $\left(Q_{i j}\right)$ for the pairwise comparison of all 13 alternative areas can be calculated and shown in Table 3 and 4 .

For the $D_{i j}$ and $Q_{i j}$ calculation example, if area $W 1$ is compared with area $W 2$,

$$
\begin{aligned}
D_{12} & =\sqrt{\begin{array}{c}
(2.47-3.95)^{2}+(2.92-3.73)^{2} \\
+(2.41-2.44)^{2}+\ldots+(2.06-3.03)^{2}
\end{array}} \\
& =2.42 \mathrm{~m} / \mathrm{s} \\
Q_{12} & =(2.47-3.95)+(2.92-3.73)+\ldots+(2.06-3.03) \\
& =0.03 \mathrm{~m} / \mathrm{s}>0 .
\end{aligned}
$$

That means the wind quality of area 2 is better than it of area 1.

With the Eqs. (3) and (4), the pairwise distance values $\left(D_{i j}\right)$ of wind energy for all 13 alternative areas in Table 3 can be converted into the AHP pairwise comparison value of the alternative area $\mathrm{i}$ and j $\left(C_{i j}\right)$.

For the $D_{i j}$ and $Q_{i j}$ calculation example, if area $W 1$ is compared with area $W 2$ with $D_{12}=2.42 \mathrm{~m} / \mathrm{s}, Q_{12}$ $=0.03 \mathrm{~m} / \mathrm{s}$ and $\max \left\{D_{i j}\right\}=8.58 \mathrm{~m} / \mathrm{s}$ (From Table 2$)$

$$
\begin{aligned}
L_{12} & =\text { round }\left[1+\frac{(8)(2.42)}{8.58}\right] \\
& =3 \text { of AHP scale } 1-9
\end{aligned}
$$

\begin{tabular}{|c|c|c|c|c|c|c|c|c|c|c|c|c|c|}
\hline \multirow[b]{2}{*}{ Alternative Areas } & \multicolumn{12}{|c|}{ Average Wind Velocity $(\mathrm{m} / \mathrm{s})$ at the height of $40 \mathrm{~m}$} & \multirow{2}{*}{$\begin{array}{c}\text { Wind Power } \\
\left(\mathrm{W} / \mathrm{m}^{2}\right)\end{array}$} \\
\hline & Jan & Feb & Mar & Apr & May & Jun & Jul & Aug & Sep & Oct & Nov & Dec & \\
\hline WI & 3.95 & 3.73 & 2.44 & 1.69 & 1.24 & 1.37 & 1.42 & 1.69 & 1.37 & 1.46 & 1.89 & 3.03 & 5.75 \\
\hline$W 2$ & 2.47 & 2.92 & 2.41 & 2.01 & 1.96 & 1.92 & 2.03 & 2.09 & 2.11 & 1.61 & 1.72 & 2.06 & 5.91 \\
\hline W3 & 4.31 & 3.93 & 3.38 & 2.76 & 2.41 & 2.67 & 2.83 & 3.05 & 2.85 & 2.52 & 2.46 & 3.88 & 17.88 \\
\hline W4 & 3.69 & 3.06 & 2.64 & 2.38 & 2.85 & 3.60 & 3.71 & 3.76 & 2.86 & 2.36 & 2.88 & 3.68 & 18.59 \\
\hline W5 & 3.77 & 3.58 & 3.21 & 2.64 & 3.27 & 3.65 & 3.71 & 4.07 & 4.03 & 3.25 & 2.77 & 3.45 & 23.84 \\
\hline W6 & 4.11 & 3.71 & 3.70 & 2.90 & 3.00 & 3.10 & 3.26 & 3.39 & 3.44 & 3.15 & 3.42 & 4.29 & 4.27 \\
\hline$W 7$ & 4.32 & 3.99 & 3.46 & 2.93 & 3.05 & 3.26 & 3.40 & 3.63 & 3.34 & 2.83 & 3.24 & 4.07 & 35 \\
\hline$W \varepsilon$ & 3.25 & 3.39 & 3.54 & 3.46 & 4.21 & 5.15 & 5.47 & 5.50 & 3.39 & 2.46 & 2.12 & 2.70 & \\
\hline W9 & 5.22 & 5.09 & 4.41 & 3.68 & 2.93 & 3.08 & 3.05 & 3.29 & 3.01 & 2.94 & 3.15 & 4.20 & 30.75 \\
\hline W10 & 5.85 & 5.53 & 4.61 & 3.60 & 2.73 & 2.78 & 2.89 & 3.22 & 2.73 & 2.83 & 3.51 & 5.01 & 32.79 \\
\hline W11 & 6.30 & 5.72 & 4.84 & 3.71 & 2.73 & 2.87 & 3.17 & 3.58 & 2.93 & 3.22 & 4.06 & 5.30 & 43.43 \\
\hline W12 & 5.02 & 5.19 & 4.52 & 3.98 & 3.61 & 3.67 & 3.89 & 4.36 & 4.07 & 3.87 & 3.67 & 5.05 & 45.02 \\
\hline W13 & 6.17 & 5.32 & 4.76 & 3.91 & 3.44 & 4.00 & 3.75 & 4.29 & 4.15 & 3.82 & 4.37 & 5.89 & 55.77 \\
\hline
\end{tabular}

Since $Q_{12}=0.03 \mathrm{~m} / \mathrm{s}>0$, then

and

\begin{tabular}{|c|c|c|c|c|c|c|c|c|c|c|c|c|c|}
\hline & & \multicolumn{12}{|c|}{ Alternative Area $i$} \\
\hline & & $W 1$ & $W 2$ & W3 & $W 4$ & W5 & W6 & $W 7$ & $W 8$ & W9 & $W 10$ & $W 11$ & $W 12$ \\
\hline \multirow{12}{*}{ 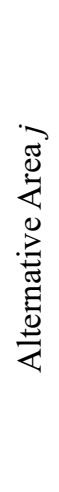 } & $W 2$ & 2.42 & & & & & & & & & & & \\
\hline & $W 3$ & 3.67 & 3.67 & & & & & & & & & & \\
\hline & $W 4$ & 4.75 & 4.00 & 2.10 & & & & & & & & & \\
\hline & $W 5$ & 5.74 & 4.90 & 2.49 & 1.78 & & & & & & & & \\
\hline & W6 & 5.15 & 4.84 & 1.69 & 2.06 & 1.72 & & & & & & & \\
\hline & $W 7$ & 5.09 & 4.81 & 1.56 & 1.79 & 1.54 & 0.69 & & & & & & \\
\hline & $W 8$ & 8.01 & 6.79 & 5.11 & 3.81 & 3.37 & 4.57 & 4.21 & & & & & \\
\hline & W9 & 5.49 & 5.75 & 2.32 & 3.59 & 3.19 & 2.15 & 1.98 & 5.28 & & & & \\
\hline & $W 10$ & 5.85 & 6.54 & 3.13 & 4.49 & 4.28 & 3.02 & 2.93 & 6.32 & 1.29 & & & \\
\hline & W11 & 6.77 & 7.45 & 3.98 & 5.11 & 4.74 & 3.56 & 3.49 & 6.64 & 2.01 & 1.05 & & \\
\hline & $W 12$ & 7.57 & 7.49 & 4.04 & 4.43 & 3.41 & 2.91 & 2.86 & 4.93 & 2.41 & 2.78 & 2.56 & \\
\hline & $W 13$ & 8.33 & 8.58 & 4.99 & 5.46 & 4.68 & 3.93 & 3.91 & 6.16 & 3.19 & 2.94 & 2.27 & 1.66 \\
\hline
\end{tabular}

$$
C_{21}=L_{12}=3
$$

$$
C_{12}=\frac{1}{L_{12}}=0.33
$$

Table 2. The average wind velocity data at the height level of $40 \mathrm{~m}$ for these 13 alternative areas [2]

Table 3. The pairwise distance value $\left(D_{i j}, \mathrm{~m} / \mathrm{s}\right)$ of wind energy comparing alternative area $i$ with alternative area $j$ 
Table 4 . The quality value $\left(Q_{i j}, \mathrm{~m} / \mathrm{s}\right)$ of wind energy comparing alternative area $i$ with alternative area $j$

\begin{tabular}{|c|c|c|c|c|c|c|c|c|c|c|c|c|c|}
\hline & \multicolumn{12}{|c|}{ Alternative Area $i$} \\
\hline & & $W 1$ & $W 2$ & $W 3$ & $W 4$ & $W 5$ & $W 6$ & $W 7$ & $W 8$ & W9 & $W 10$ & $W 11$ & $W 12$ \\
\hline \multirow{12}{*}{ 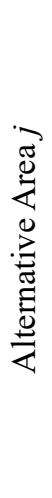 } & $W 2$ & 0.03 & & & & & & & & & & & \\
\hline & $W 3$ & 11.77 & 11.74 & & & & & & & & & & \\
\hline & $W 4$ & 12.19 & 12.16 & 0.42 & & & & & & & & & \\
\hline & $W 5$ & 16.12 & 16.09 & 4.35 & 3.93 & & & & & & & & \\
\hline & $W 6$ & 16.19 & 16.16 & 4.42 & 4.00 & 0.07 & & & & & & & \\
\hline & $W 7$ & 16.24 & 16.21 & 4.47 & 4.05 & 0.12 & 0.05 & & & & & & \\
\hline & $W 8$ & 19.36 & 19.33 & 7.59 & 7.17 & 3.24 & 3.17 & 3.12 & & & & & \\
\hline & $W 9$ & 18.77 & 18.74 & 7.00 & 6.58 & 2.65 & 2.58 & 2.53 & -0.59 & & & & \\
\hline & $W 10$ & 20.01 & 19.98 & 8.24 & 7.82 & 3.89 & 3.82 & 3.77 & 0.65 & 1.24 & & & \\
\hline & W11 & 23.15 & 23.12 & 11.38 & 10.96 & 7.03 & 6.96 & 6.91 & 3.79 & 4.38 & 3.14 & & \\
\hline & $W 12$ & 25.62 & 25.59 & 13.85 & 13.43 & 9.50 & 9.43 & 9.38 & 6.26 & 6.85 & 5.61 & 2.47 & \\
\hline & $W 13$ & 28.59 & 28.56 & 16.82 & 16.40 & 12.47 & 12.40 & 12.35 & 9.23 & 9.82 & 8.58 & 5.44 & 2.97 \\
\hline
\end{tabular}

Table 5. The AHP pairwise comparison matrix for all 13 alternative areas

\begin{tabular}{|c|c|c|c|c|c|c|c|c|c|c|}
\cline { 2 - 12 } \multicolumn{1}{c|}{} & $W 1$ & $W 2$ & $W 3$ & $W 4$ & $W 5$ & $W 6$ & $W 7$ & $W 8$ & $W 9$ & $W 10$ \\
\hline$W 1$ & 1 & 0.3333 & 0.2500 & 0.2000 & 0.1667 & 0.1667 & 0.1667 & 0.1250 & 0.1667 & 0.1667 \\
\hline$W 2$ & 3 & 1 & 0.2500 & 0.2000 & 0.1667 & 0.1667 & 0.2000 & 0.1429 & 0.1667 & 0.1429 \\
\hline$W 3$ & 4 & 4 & 1 & 0.3333 & 0.3333 & 0.3333 & 0.5000 & 0.1667 & 0.3333 & 0.2500 \\
\hline$W 4$ & 5 & 5 & 3 & 1 & 0.3333 & 0.3333 & 0.3333 & 0.2000 & 0.2500 & 0.2000 \\
\hline$W 5$ & 6 & 6 & 3 & 3 & 1 & 0.3333 & 0.5000 & 0.2500 & 0.2500 & 0.2000 \\
\hline$W 6$ & 6 & 6 & 3 & 3 & 3 & 1 & 0.5000 & 0.2000 & 0.3333 & 0.2500 \\
\hline$W 7$ & 6 & 5 & 2 & 3 & 2 & 2 & 1 & 0.2000 & 0.3333 & 0.2500 \\
\hline$W 8$ & 8 & 7 & 6 & 5 & 4 & 5 & 5 & 1 & 6 & 0.1429 \\
\hline$W 9$ & 6 & 6 & 3 & 4 & 4 & 3 & 3 & 0.1667 & 1 & 0.5000 \\
\hline$W 10$ & 6 & 7 & 4 & 5 & 5 & 4 & 4 & 7 & 2 & 1 \\
\hline$W 11$ & 7 & 8 & 5 & 6 & 5 & 4 & 4 & 7 & 3 & 2 \\
\hline$W 12$ & 8 & 8 & 6 & 5 & 4 & 4 & 4 & 6 & 3 & 4 \\
\hline$W 13$ & 9 & 9 & 6 & 6 & 5 & 5 & 5 & 7 & 4 & 4 \\
\hline
\end{tabular}

\begin{tabular}{|c|c|c|c|}
\cline { 2 - 4 } \multicolumn{1}{c|}{} & $W 11$ & $W 12$ & $W 13$ \\
\hline$W 1$ & 0.1429 & 0.1250 & 0.1111 \\
\hline$W 2$ & 0.1250 & 0.1250 & 0.1111 \\
\hline$W 3$ & 0.2000 & 0.1667 & 0.1667 \\
\hline$W 4$ & 0.1667 & 0.2000 & 0.1667 \\
\hline$W 5$ & 0.2000 & 0.2500 & 0.2000 \\
\hline$W 6$ & 0.2500 & 0.2500 & 0.2000 \\
\hline$W 7$ & 0.2500 & 0.2500 & 0.2000 \\
\hline$W 8$ & 0.1429 & 0.1667 & 0.1429 \\
\hline$W 9$ & 0.3333 & 0.3333 & 0.2500 \\
\hline$W 10$ & 0.5000 & 0.2500 & 0.2500 \\
\hline$W 11$ & 1 & 0.3333 & 0.3333 \\
\hline$W 12$ & 3 & 1 & 0.3333 \\
\hline$W 13$ & 3 & 3 & 1 \\
\hline
\end{tabular}

Finally, The AHP pairwise comparison matrix for all 13 alternative areas is constructed as shown in Table 5.

Next, each value in each cell of the AHP pairwise comparison matrix is divided by its corresponding column sum to normalize all values of $C_{i j}$ and transfer all values of $C_{i j}$ to the values of $N_{i j}$ as shown in Table 6.

Lastly, the Eq. (5) is applied to the values of $\mathrm{N}_{\mathrm{ij}}$ so that the priority values for all 13 alternative areas are calculated and the priority values of each alternative area are as follows:

$$
\begin{aligned}
P_{W 1} & =\frac{0.0133+0.0046+0.0059+\cdots+0.0321}{13} \\
& =0.0105 \\
P_{W 2} & =\frac{0.0400+0.0138+0.0059+\ldots+0.0321}{13} \\
& =0.0131
\end{aligned}
$$

DOI: $10.22266 /$ ijies2021.1231.33 
Table 6. The AHP normalized matrix for all 13 alternative areas

\begin{tabular}{|c|c|c|c|c|c|c|c|c|c|c|}
\cline { 2 - 12 } \multicolumn{1}{c|}{} & $W 1$ & $W 2$ & $W 3$ & $W 4$ & $W 5$ & $W 6$ & $W 7$ & $W 8$ & $W 9$ & $W 10$ \\
\hline$W 1$ & 0.0133 & 0.0046 & 0.0059 & 0.0048 & 0.0049 & 0.0057 & 0.0059 & 0.0042 & 0.0080 & 0.0127 \\
\hline$W 2$ & 0.0400 & 0.0138 & 0.0059 & 0.0048 & 0.0049 & 0.0057 & 0.0071 & 0.0049 & 0.0080 & 0.0109 \\
\hline$W 3$ & 0.0533 & 0.0553 & 0.0235 & 0.0080 & 0.0098 & 0.0114 & 0.0177 & 0.0057 & 0.0160 & 0.0191 \\
\hline$W 4$ & 0.0667 & 0.0691 & 0.0706 & 0.0240 & 0.0098 & 0.0114 & 0.0118 & 0.0068 & 0.0120 & 0.0153 \\
\hline$W 5$ & 0.0800 & 0.0829 & 0.0706 & 0.0719 & 0.0294 & 0.0114 & 0.0177 & 0.0085 & 0.0120 & 0.0153 \\
\hline$W 6$ & 0.0800 & 0.0829 & 0.0706 & 0.0719 & 0.0882 & 0.0341 & 0.0177 & 0.0068 & 0.0160 & 0.0191 \\
\hline$W 7$ & 0.0800 & 0.0691 & 0.0471 & 0.0719 & 0.0588 & 0.0682 & 0.0355 & 0.0068 & 0.0160 & 0.0191 \\
\hline$W 8$ & 0.1067 & 0.0968 & 0.1412 & 0.1198 & 0.1176 & 0.1705 & 0.1773 & 0.0340 & 0.2880 & 0.0109 \\
\hline$W 9$ & 0.0800 & 0.0829 & 0.0706 & 0.0958 & 0.1176 & 0.1023 & 0.1064 & 0.0057 & 0.0480 & 0.0382 \\
\hline$W 10$ & 0.0800 & 0.0968 & 0.0941 & 0.1198 & 0.1471 & 0.1364 & 0.1418 & 0.2377 & 0.0960 & 0.0763 \\
\hline$W 11$ & 0.0933 & 0.1106 & 0.1176 & 0.1438 & 0.1471 & 0.1364 & 0.1418 & 0.2377 & 0.1440 & 0.1526 \\
\hline$W 12$ & 0.1067 & 0.1106 & 0.1412 & 0.1198 & 0.1176 & 0.1364 & 0.1418 & 0.2037 & 0.1440 & 0.3053 \\
\hline$W 13$ & 0.1200 & 0.1244 & 0.1412 & 0.1438 & 0.1471 & 0.1705 & 0.1773 & 0.2377 & 0.1920 & 0.3053 \\
\hline
\end{tabular}

\begin{tabular}{|c|c|c|c|}
\cline { 2 - 4 } \multicolumn{1}{c|}{} & $W 11$ & $W 12$ & $W 13$ \\
\hline$W 1$ & 0.0153 & 0.0194 & 0.0321 \\
\hline$W 2$ & 0.0134 & 0.0194 & 0.0321 \\
\hline$W 3$ & 0.0215 & 0.0258 & 0.0481 \\
\hline$W 4$ & 0.0179 & 0.0310 & 0.0481 \\
\hline$W 5$ & 0.0215 & 0.0388 & 0.0577 \\
\hline$W 6$ & 0.0269 & 0.0388 & 0.0577 \\
\hline$W 7$ & 0.0269 & 0.0388 & 0.0577 \\
\hline$W 8$ & 0.0153 & 0.0258 & 0.0412 \\
\hline$W 9$ & 0.0358 & 0.0517 & 0.0721 \\
\hline$W 10$ & 0.0537 & 0.0388 & 0.0721 \\
\hline$W 11$ & 0.1074 & 0.0517 & 0.0962 \\
\hline$W 12$ & 0.3222 & 0.1550 & 0.0962 \\
\hline$W 13$ & 0.3222 & 0.4651 & 0.2886 \\
\hline
\end{tabular}

$$
\begin{aligned}
P_{W 3} & =\frac{0.0533+0.0553+0.0235+\ldots+0.0481}{13} \\
& =0.0242
\end{aligned}
$$

$$
\begin{aligned}
P_{W 13} & =\frac{0.1200+0.124 \dot{4}+0.1412+\ldots+0.2886}{13} \\
& =0.02181 .
\end{aligned}
$$

Finally, all priority values of 13 alternative areas are $P_{W 1}=0.0105, P_{W 2}=0.0131, P_{W 3}=0.0242, P_{W 4}=$ $0.0303, P_{W 5}=0.0398, P_{W 6}=0.0470, P_{W 7}=0.0458$, $P_{W 8}=0.1035, P_{W 9}=0.0698, P_{W 10}=0.1070, P_{W 11}=$ $0.1292, P_{W 12}=0.1616$ and $P_{W 13}=0.2181$ with $C . R .=$ 0.1157 (Calculated by the Eq. (6) - (9)). Now, the ranking of wind energy priority of 13 alternative areas with AHP is $W 1, W 2, W 3, W 4, W 5, W 7, W 6$, $W 9, W 8, W 10, W 11, W 12$ and $W 13$, respectively.

If compare the wind energy potential of all 13 alternative areas by the AHP priority values with the wind energy potential of all 13 alternative areas by the wind power as shown in Table 7, both methods receive almost the same results. There are different only at the $6^{\text {th }}$ and $7^{\text {th }}$ of ranking position and the $8^{\text {th }}$ and $9^{\text {th }}$ of ranking position.

\section{Conclusion}

This study is to introduce the AHP method for evaluating the wind energy potential. With AHP method, the secondary data of average wind velocity along 12 months of a year are the main input data that is different from using the data of wind power in the conventional method which has to prepare a lot of budget for data collecting process and has some bias in AHP pairwise comparison process. In the case study, 13 alternative areas in the south of Thailand are analyzed with the AHP method. Finally, the priority result with the AHP priority values is almost the same results with the conventional method. This shows that the simply data like the secondary data of average wind velocity along 12 months of a year can be analyzed with the five main steps to receive the priority results with a low cost for data collecting process and without any bias in AHP pairwise comparison process.

\section{Conflicts of Interest}

The authors declare no conflict of interest. 


\section{Author Contributions}

The paper conceptualization, methodology, software, validation, formal analysis, investigation, resources, data curation, writing-original draft preparation, writing-review and editing, and visualization, have been done by the $1^{\text {st }}$ author. The supervision and project administration have been done by the $2^{\text {nd }}$ author.

\section{References}

[1] Department of Alternative Energy Development and Efficiency, Ministry of Energy dataset: https:// www.dede.go.th/download/stat63/fontpage_dec202 0.pdf

[2] T. Unchai, A. Janyalertadum, and A. E. Hold, "Wind Energy Potential Assessment as Power Generation Source in Ubonratchathani Province, Thailand", Wind Engineering, Vol. 36, No. 2, pp. 131-144, 2012.

[3] S. Chingulpitak and S. Wongwises, "Critical Review of the Current Status of Wind Energy in Thailand", Renewable and Sustainable Energy Reviews, Vol. 31, pp. 312-318, 2014.

[4] P. Quan and T. Leephakpreeda, "Assessment of Wind Energy Potential for Selecting Wind Turbines: An Application to Thailand", Sustainable Energy Technologies and Assessments, Vol. 11, pp. 17-26, 2015.

[5] M. J. Liberatore, "An Extension of the Analytic Hierarchy Process for Industrial R\&D Project Selection and Resource Allocation", IEEE Transactions on Engineering Management, Vol. EM 34, No. 1, pp. 12-18, 1987.

[6] M. Kurttila, M. Pesonen, J. Kangas, and M. Kajanus, "Utilizing the Analytic Hierarchy Process AHP in SWOT Analysis - A Hybrid Method and Its Application to a Forest Certification Case", Forest Policy and Economic, Vol. 1, pp. 41-52, 2000.

[7] R. Handfield, S. V. Walton, R. Sroufe, and S. A. Melnyk, "Applying Environmental Criteria to Supplier Assessment: A Study in the Application of the Analytical Hierarchy Process", European Journal of Operational Research, Vol. 141, pp. 70-87, 2002.

[8] A. C. Brent, D. E. Rogers, T. S. M. R. Siimane, and M. B. Rohwer, "Application of the Analytical Hierarchy Process to Establish Health Care Waste Management Systems that Minimise Infection Risks in Developing Countries", European Journal of Operational Research, Vol. 181, pp. 403-424, 2007.

[9] A. R. Karimi, N. Mehrdad, S. J. Hashemian, G. R. N. Bidhendi, and R. T. Moghaddam,
"Selection of Wastewater Treatment Process Based on the Analytical Hierarchy Process and Fuzzy Analytical Hierarchy Process Methods", International Journal Environment Science Technology, Vol. 8, No. 2, pp. 267-280, 2011.

[10] O. Erol and B. Kilkis, "An Energy Source Policy Assessment Using Analytical Hierarchy Process", Energy Conversion and Management, Vol. 63, pp. 245-252, 2012.

[11] J. E. Leal, "AHP-Express: A Simplified Version of the Analytical Hierarchy Process Method", MethodsX, Vol. 7, pp. 1-11, 2020.

[12] R. L. Bulhoes, E. S. Santana, and A. B. Santos, "Use of Analytic Hierarchy Process for Wind Farm Installation Region Prioritization-Case Study", Energies, Vol. 13, No. 9, 2020.

[13] Department of Alternative Energy Development and Efficiency, Ministry of Energy dataset: http:// www2.dede.go.th/km_it/windmap40m/windma p $40 \mathrm{~m} \cdot \mathrm{html}$

[14] H. A. Donegan and F. J. Dodd, "Note on Saaty's Random Indexes", Mathematical and Computer Modelling, Vol. 15, No. 10, pp. 135137, 1991. 